\title{
Undergraduate degrees in photonics in Ontario, Canada
}

\section{Marc Nantel, Johann Beda, Paul Jessop, Shaowen Song}

Marc Nantel, Johann Beda, Paul Jessop, Shaowen Song, "Undergraduate degrees in photonics in Ontario, Canada," Proc. SPIE 9663, Eighth International Topical Meeting on Education and Training in Optics and Photonics, 966304 (6 October 2003); doi: 10.1117/12.2208372

SPIE Event: Eighth International Topical Meeting on Education and Training in Optics and Photonics, 2003, Tucson, Arizona, United States 


\title{
Undergraduate degrees in photonics in Ontario, Canada
}

\author{
Marc Nantel, Johann Beda \\ Photonics Research Ontario, Suite 331, 60 St-George Street, Toronto, ON, Canada M5S 1 A7 \\ (416)978-3932, (416)978-3936 (fax), mnantel@pro.on.ca, curriculum@pro.on.ca \\ Paul Jessop \\ Department of Engineering Physics, McMaster University, Hamilton, ON, Canada \\ pjessop@mcmaster.ca \\ Shaowen Song \\ Department of Physics and Computer Science, Wilfrid Laurier University, Waterloo, ON, Canada \\ ssong@wlu.ca
}

\begin{abstract}
In the last year, three very different new undergraduate degrees in photonics have started to develop in Ontario where none was available before. One is an Honours B.Sc. in Photonics, one is a Photonics Engineering degree and another is a Bachelor of Applied Technology in Photonics. This paper presents these programs.

(C)2003 Optical Society of America

OCIS codes: (000.2060) Education, (000.1200) Announcements, awards, news, and organizational activities
\end{abstract}

Until recently, the only photonics education programs in Ontario were at the province's universities' graduate schools, which produced Masters and PhDs only. After the introduction in 2001 of community college programs at the Technician/Technologist levels and in 2002 of professional development programs for currently-employed scientists and engineers, the need to cover the educational space at the undergraduate level was addressed. In this paper, we present three new programs that are approaching photonics from different directions, and that will produce different graduates: Bachelors of Applied Technology, Bachelors of Science, and Bachelors of Engineering.

Niagara College and Algonquin College, two Ontario community colleges, already strong from their programs in Photonics Engineering Technician/Technologists, have been given permission by the Ontario Ministry of Training, Colleges and Universities to offer a 4-year Bachelor of Applied Technology (Photonics). The concept of 4-year degrees at the community-college level is a new one in Ontario, and competition was fierce in obtained the few allowed permissions. The college program is joint between the two institutions, with a common curriculum, shared library resources, student exchanges between the two colleges and co-op work-terms. Emphasis is placed on the applied aspect of the field, with the more hands-on experimental learning taking precedence in the first years and the more advanced theoretical subjects following in the latter years. This is a reversal from the usual sequence in a degree program, and the merits of this approach will be discussed. This program is in preparation for a first student intake in September 2004.

Wilfrid Laurier University's Department of Physics and Computer Science is launching its new Honours BSc Photonics with its first student intake in September 2003. The aim of the program is to develop a strong understanding of the theory and application of photonics, with specific emphasis on data communications and networks, and with practical hands-on exposure to optics, fibre optics, and lasers. Wilfrid Laurier University's program benefits from the particularity that the department offering it combines both Physics and Computer Science, and that the thrust of the program would reflect this combination.

McMaster University's new Photonics Engineering program will be offered by the Department of Engineering Physics, and will be the first Engineering program of its kind in Canada. Like the existing Engineering Physics program, it will provide students with a broad background in basic Engineering, Mathematics, Electronics, and Semiconductors. However, the new program will provide students an opportunity to pursue Photonics in greater depth and to have that fact recognized in the program designation. Following McMaster's successful pattern of fiveyear Engineering programs, a new B.Eng. in Photonics Engineering and Management and another in Photonics Engineering and Society will be introduced in parallel with the four-year program. The first students are expected to enter Level II in September 2003, with the first class graduating in the spring of 2006.

Eighth International Topical Meeting on Education and Training in Optics and Photonics,

edited by Barry L. Shoop, Grover Swartzlander Jr., Proc. of SPIE Vol. 9663, 966304

(C) 2003 SPIE, OSA, ICO · doi: 10.1117/12.2208372 